\title{
The Literature Review of Proactive Behavior at Work
}

\author{
Xuanfang $\mathrm{Hou}^{1}$, Rong Huang ${ }^{1 *}$ \\ ${ }^{1}$ School of Business, Jiangxi Normal University \\ *Corresponding author. Email: 1373105752@qq.com
}

\begin{abstract}
With the intensification of market competition, organization gradually expects employees' proactive behavior to help organization cope with market changes. Therefore, the research of proactive behavior is helpful to deepen our understanding of it. In view of this, the paper defines the connotation and dimensions of proactive behavior based on previous literature, organizes the latest research results on the mechanism of employees' proactive behavior from three aspects: antecedent, intermediary and regulation, finds out the shortcomings in the current research field, and looks forward to the future development of the research.
\end{abstract}

Keywords: Proactive Behavior, Generation Mechanism, Research Status.

\section{INTRODUCTION}

Without instructions, Subordinates have prepared all the materials needed for leaders to attend meetings or actively ask their superiors for feedback about their performance in order to improve the quality of their work. This kind of behavior, which is future-oriented, tries to change their own situation and actively completes and exceeds the requirements of work tasks, is called proactive behavior (Belschak et al., 2010). In the workplace, the fierce competition in the market leads to the organization changing for gaining market competitiveness actively, which depends largely on the proactive behavior of employees. Organizations want to change the management mode of "one instruction, one execution" into a more flexible work pattern, which requires employees to keep initiative, dare to challenge, have higher work passion and vitality, and thus implement more proactive behaviors (Pingel et al., 2019). In order to understand and develop employees' proactive behavior better, this paper aims to systematically sort out and define proactive behavior from the connotation and dimensions, and systematically comb the latest academic research, clarify the research context of existing research, find out the shortcomings, and put forward the directions for future research.

\section{PROACTIVE BEHAVIOR AT WORK}

Proactive behavior refers to the self-started behavior of employees in the workplace that goes beyond the role and aims to bring about changes in view of the future problems in the organization (Urbach et al., 2019). Because it can be effectively expressed in a highly competitive work environment, which is dynamic and changeful, proactive behavior is desired by the organizations. Scholars defined proactive behavior as an initiative and self-started work behavior adopted by employees in order to overcome difficulties or pursue goals. However, this concept has some limitations, which only involves the work behaviors these are beneficial to the organization, while ignoring the behaviors that are only beneficial to oneself but harm others or organizations, thus lacking universality. Therefore, based on it, some scholars define proactive behavior as the expected actions taken by employees to influence themselves or the environment, that is, "to create or control the situation by taking the initiative or predicting events (instead of responding to them)" (Grant et al., 2008). To sum up, proactive behavior is an advance action with future orientation, change orientation and spontaneity, which may not be completely beneficial to the organization, but may bring destructive rather than constructive influence to the organization.

\section{THE DIMENSIONS OF PROACTIVE BEHAVIOR}

As the researchers pay more and more attention to the study of proactive behavior, they immediately discuss the dimension division and scale development of proactive behavior after defining its concept (as shown in Table 1), which lays a foundation for subsequent research. 


\section{MOTIVATIONAL MECHANISMS}

\subsection{Antecedents of Proactive Behavior}

Based on the current researches, scholars mostly analyze the positive effects of individual factors (individual attitude, personality traits, knowledge ability, emotional cognition, etc.), job characteristics (work autonomy, work complexity, time pressure, etc.), and organizational factors (supervisor support, leadership style, etc.) on proactive behavior, which will also have negative effects on proactive behavior. See figure 1 for details.

Table 1 Aspects of Proactive Behavior.

\begin{tabular}{cc}
\hline Authors & Aspects \\
\hline $\begin{array}{c}\text { Crant et } \\
\text { al.(2000) }\end{array}$ & General proactive behavior \\
Parker et & Proactive idea implementation, Proactive \\
al.(2006) & problem solving \\
Griffin et & Individual Task Proactivity, Team Member \\
al.(2007) & Proactivity, Organization Member \\
& Proactivity \\
Parker et & Proactive Work Behavior, Proactive \\
al.(2010) & Person-environment (PE) Fit Behavior, \\
Bindl et & Proactive Strategic Behavior \\
al.(2012) & Envisioning, Planning, Enacting, and \\
Grant et & Reflecting \\
al.(2008) & Form, target, frequency, time, tactic \\
\hline
\end{tabular}

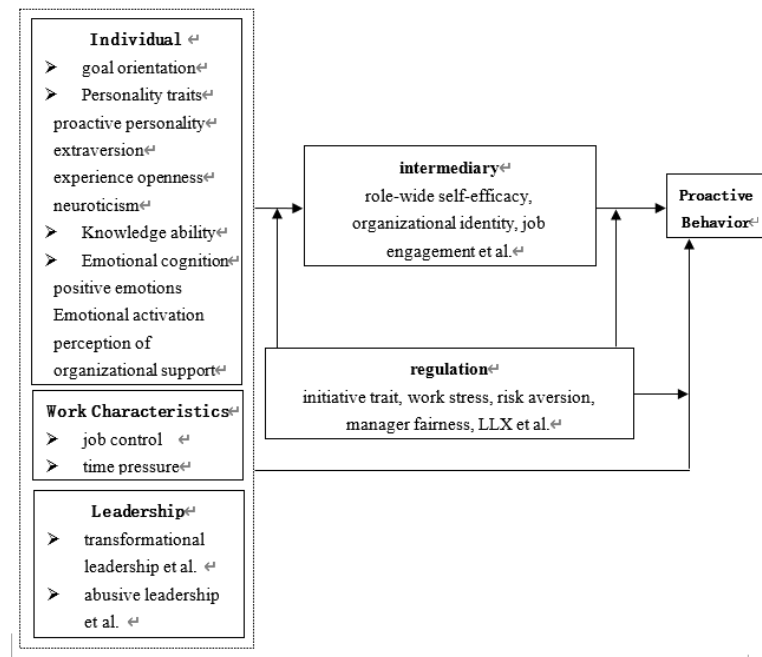

Figure 1 Model of Proactive Behavior.

\subsubsection{Individual antecedents}

Individual factors mainly include individual attitude, personality traits, knowledge ability, emotional cognition and so on.
In terms of attitude, when employees are open to change or have high learning goal orientation or proof goal orientation, they will be more inclined to show proactive behaviors such as taking responsibility and innovating (Tan et al., 2016); however, not all goal orientations can positively promote it. Individuals with high performance or avoidance goal orientation are aware of the uncertainty and risk of proactive behavior. Therefore, in order to avoid the risk of it, they choose to maintain the status quo, and such employees are unlikely to take proactive behavior.

From the perspective of personality traits, scholars believe that individuals with proactive personality or active personality traits are more inclined to implement proactive behavior; Moreover, individuals with extraversion and experience openness tend to implement proactive behavior, while neuroticism negatively predicts proactive behavior (Tornau et al., 2013). From the perspective of knowledge ability, due to the implementation of proactive behavior needs a certain knowledge base as the cornerstone (Parker et al., 2010), employees with higher knowledge ability level are more likely to take active actions.

As for the emotional cognition, positive emotions, which are regarded as resources, can promote the generation of individual forward-looking behavior. However, some scholars have found that the main factor prompting employees to implement proactive behavior is not emotion itself, but emotional activation state (Bindl et al., 2012). In addition, perception of organizational support has an inverted U-shaped influence on proactive behavior.

\subsubsection{Work characteristic antecedents}

Job characteristics mainly include job autonomy, time pressure and so on. Job control or job autonomy can promote employees' proactive behavior. Compared with employees with low job autonomy, employees with high job autonomy or job control have a wider range of resource control, which can not only reduce obstacles during the process of achieving goals, and strive to set higher goals for themselves, thus making it easier to initiate behaviors beyond formal job requirements (including but not limited to proactive behaviors), but also have stronger internal job motivation (Sonnentag et al., 2012). In addition, time pressure has an inverted Ushaped relationship with proactive behavior. Appropriate pressure can stimulate proactive behavior, while the excessive or long-term tension will lead to negative psychological impact on employees. And then, for the purpose of resource conservation, employees will devote more resources to work-related role behaviors to ensure that tasks are completed on time, and will not promote or even worsen the initiative (Urbach et al., 2019). 


\subsubsection{Leadership antecedents}

Leaders have an important influence on employee behavior. For example, transformational leaders stimulate and empower employees to question, jumping out of the inherent thinking mode, and then point out work problems, which transforms the command into employees' spontaneous behaviors, so that employees are more likely to actively achieve their proposed work goals and take proactive actions in their work (Schmitt et al., 2016). And Self-sacrificing leaders improve employees' intrinsic motivation to implement proactive behaviors that are beneficial to the organization by promoting subordinates' internalization of the value and importance of responsibility and meeting their basic psychological needs such as ability and relationship (Li et al., 2016).

As for abusive leadership, it leads to the damage of subordinates' self-confidence and work image, which bring about the depression and reduction of sense of belonging, and finally leads to the reduction of the internal motivation, instead of spending time and energy on proactive behavior (Xu et al., 2015). Authoritarian leaders, who require subordinates to obey absolutely and not accept doubts, lack emotional communication with subordinates, which make it difficult to establish an exchange relationship between them, so this kind of leaders can not really stimulate subordinates' proactive behavior beyond the scope of roles.

\subsection{Mediating and Moderating Influences}

At present, the mediating role of proactive behavior in academic circles has been verified by role-wide selfefficacy, organizational identity, work engagement and so on. Role-wide self-efficacy mediates the relationship between job control and proactive behavior (Sonnentag et al., 2012). Because employees with high job control think that the reason why leaders give them high job control is that leaders believe they have enough ability to complete the tasks, thus promoting their enactive mastery and proactive behavior.

And then, organizational identity mediates the positive relationship between self-sacrificing leadership and proactive behavior ( $\mathrm{Li}$ et al., 2016). Self-sacrificing leadership conveys to subordinates that it is worthwhile to sacrifice for the collective, which will have an impact on subordinates' organizational identity. By internalizing organizational mission and values, it will increase subordinates' intrinsic motivation to implement proactive behavior. Furthermore, job engagement can play an intermediary role as well (Schmitt et al., 2016). Transformational leadership promotes employees' job involvement by enhancing their awareness of the significance and importance of work, and indirectly affects the implementation of employees' proactive behavior.
In addition, the proven moderating effects include initiative, work stress, risk aversion, manager fairness, and so on. Individuals with active characteristics may take the expected positive emotion as the motivation to implement behavior. When the employee thinks that he feels good, he does not need to take active behavior to obtain positive emotion, and then his proactive behavior will not increase. When employees are under high work pressure, individual resources are consumed at a high speed. To protect surplus resources from excessive consumption, individuals will also choose to reduce their investment in disposable work behaviors. Only when the work pressure is low can employees devote extra resources to active work behavior (Schmitt et al., 2016).

Moreover, employees with risk aversion will try their best to avoid the negative consequences brought by proactive behavior. Such groups are unwilling to bear the hidden risks of proactive behavior, and even with the support or encouragement of leaders, they are unwilling to implement it ( $\mathrm{Li}$ et al., 2016). As for manager fairness, which is regarded as an important work resource, will also have an impact on employees' emotional behavior.

\section{LIMITATIONS AND FUTURE DIRECTIONS}

To sum up, proactive behavior has been widely concerned by scholars, and a lot of researches have been done on proactive behavior, and many research results have been obtained. However, there are still some research problems that are not clear yet.

Most of the existing researches set proactive behavior as constructive behavior, and seldom involve the dark side of it. But employees will also choose negative behavior to cope with work difficulties, such as taking feedback avoidance strategies to avoid being punished, getting higher benefits through whistleblowing which will harm the interests of the organization. Therefore, further distinguishing the tendency of proactive behavior and exploring the mechanism of negative proactive behavior will help managers better manage employees and provide some reference for them to avoid this employee behavior.

Organizational change requires employees' initiative, and competition is the key factor to bring catfish effect. Therefore, whether team competition will affect employees' proactive behavior and through what path will it affect employees' proactive behavior has not been explained by scholars. Faced with the increasing demand and the challenge of limited resources, organizations must do more things with less resources to maintain competitiveness. So, organizations increasingly expect employees to participate in proactive behavior, and seek ways to stimulate it. A competition atmosphere becomes an important means to 
achieve this goal. Previous studies mostly regard team competition as situational factors, but seldom explore the internal mechanism between proactive behavior and it. Future studies can make breakthroughs in it.

In addition, scholars mainly focus on supervisor's support and leadership style, and seldom involve the phenomenon of "insiders" and "outsiders" caused by comparison, which provides us with research ideas. The identity perception of insiders and outsiders will affect employees' work enthusiasm. Employees who feel they belong to insiders will have a closer relationship with leaders and are more likely to reward leaders through positive work behavior, while employees who feel they are outsiders are more difficult to implement positive proactive behavior. On the contrary, negative proactive behavior may occur to cope with this differential treatment phenomenon. And future research can further explore the influence of the differential atmosphere on employees' proactive behavior.

Finally, scholars often explore the situational impact of individual traits and thinking cognition on proactive behavior. The impact of cognitive conflict and runningin brought by culture itself or cultural diversity on employees' proactive behavior has not received too much attention from academic circles, and there are few related researches. China's unique interpersonal interaction characteristics, face consciousness, and localized situational characteristics such as emphasizing moderation and harmony have led employees to tend to be self-disciplined, and choose to stick to their job responsibilities and avoid showing off out of the consideration of shooting first birds. Such people will not choose proactive behavior to a greater extent in the workplace. Compared with western countries, this kind of phenomenon is more common in Chinese enterprises, so how to stimulate the positive proactive behavior of this kind of groups and then improve organizational performance needs further in-depth analysis.

\section{CONCLUSION}

In general, the research about proactive behavior is relatively mature, but there are still some problems need to be resolved. We encourage the future studies that may be able to focus on the dark side of proactive behavior further, and then seek the corresponding solution. In addition, the studies can pay attention to the influence factors of proactive behavior in many aspects such as identity perception because of the insider and outsider, like the influence of the differential atmosphere on employees' proactive behavior, and that consider the interaction effects with situational factors.

\section{ACKNOWLEDGMENTS}

This study was supported by a grant from the National Natural Science Foundation of China (71562021). And the main research field is organizational behavior and human resource management.

\section{REFERENCES}

[1] F.D. Belschak, Being proactive at work - blessing or bane[J]. Psychologist, 2010, 23(11):886-889.

[2] T. Urbach, O. Weigelt, Time pressure and proactive work behavior: A week level study on intraindividual fluctuations and reciprocal relationships $[\mathrm{J}]$. Journal of Occupational and Organizational Psychology, 2019, 92(4):931-952.

[3] A.M. Grant, S.J. Ashford, The dynamics of proactivity at work[J]. Research in organizational behavior, 2008(28):3-34.

[4] U.K. Bindl, S.K. Parker, P. Totterdell, G. HaggerJohnson, Fuel of the Self-Starter: How Mood Relates to Proactive Goal Regulation[J]. Journal of Applied Psychology, 2012, 97(1):134-150.

[5] K.W.T. Tan, A.K.C. Au, H.D. Cooper-Thomas, S.S.Y. Aw, The effect of learning goal orientation and communal goal strivings on newcomer proactive behaviors and learning $[\mathrm{J}]$. Journal of Occupational \& Organizational Psychology, 2016, 89(2): 420-445.

[6] K.Tornau, M. Frese, Construct clean-up in proactivity research: A Meta-Analysis on the Nomological Net of Work-Related Proactivity Concepts and their Incremental Validities[J]. Applied Psychology: An International Review. 2013;62(1):44-96.

[7] S. Sonnentag, A. Spychala, Job control and job stressors as predictors of proactive work behavior: Is role breadth self-efficacy the $\operatorname{link}[\mathrm{J}]$. Human Performance, 2012, 25(6), 412-431.

[8] A. Schmitt, D.N. Den Hartog, F.D. Belschak. Transformational leadership and proactive work behavior: A moderated mediation model including work engagement and job strain[J]. Journal of Occupational \& Organizational Psychology, 2016: 588-610.

[9] R. Li, Z.Y. Zhang, X.M. Tian, Can self-sacrificial leadership promote subordinate taking charge? The mediating role of organizational identification and the moderating role of risk aversion[J]. Journal of Organizational Behavior, 2016, 37: 758- 781.

[10] X. Qing, X. Meng, Z. Shuming, Abusive Supervision and Subordinate Proactive Behavior: Exploring the Effects of Work Engagement and Core Self-Evaluations[J]. Journal of Management, 2015, 12(03):347-354. 